\title{
Molecular Fractionation of Dissolved Organic Matter in a Shallow Subterranean Estuary: The Role of the Iron Curtain
}

\author{
Annika Linkhorst, ${ }^{*}, \neq, \$ \odot$ Thorsten Dittmar, ${ }^{*}$ and Hannelore Waska ${ }^{*}$, \\ ${ }^{\dagger}$ Institute of Biogeochemistry and Pollutant Dynamics, ETH Zurich, 8092 Zurich, Switzerland \\ ${ }^{\ddagger}$ Research Group for Marine Geochemistry (ICBM-MPI Bridging Group), Institute for Chemistry and Biology of the Marine \\ Environment (ICBM), University of Oldenburg, 26129 Oldenburg, Germany
}

\section{Supporting Information}

ABSTRACT: Iron that precipitates under aerobic conditions in natural aquatic systems scavenges dissolved organic matter (DOM) from solution. Subterranean estuaries (STEs) are of major importance for land-ocean biogeochemical fluxes. Their specific redox boundaries, coined the "iron curtain" due to the abundance of precipitated iron(III) (oxy)hydroxides, are hot spots for the removal and redissolution of iron, associated nutrients, and DOM. We used ultra-high-resolution electrospray ionization Fourier transform ion cyclotron resonance mass spectrometry to molecularly characterize the ironcoagulating fractions of 32 groundwater and seawater DOM

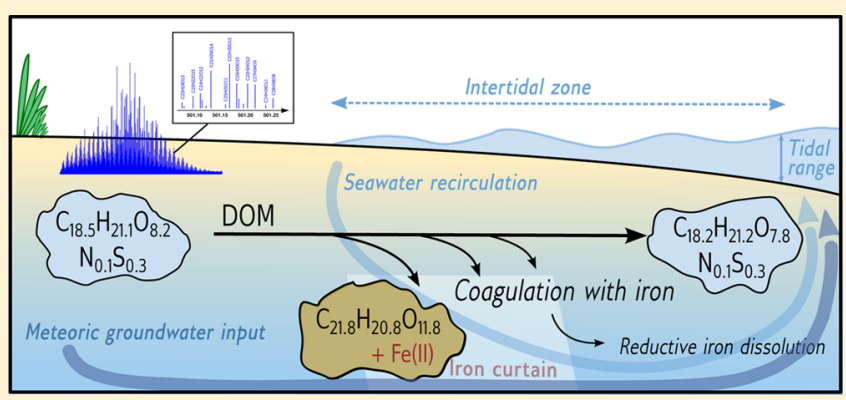
samples along a salinity gradient from a shallow STE on Spiekeroog Island, North Sea, Germany, and linked our findings to trace metal and nutrient concentrations. We found systematic iron coagulation of large (>450 Da), oxygen-rich, and highly aromatic DOM molecules of terrestrial origin. The extent of coagulation increased with growing terrestrial influence along the salinity gradient. Our study is the first to show that the iron curtain may be capable of retaining terrigenous DOM fractions in marine sediments. We hypothesize that the iron curtain serves as an inorganic modulator for the supply of DOM from groundwaters to the sea, and that the STE has the potential to act as a temporal storage or even sink for terrigenous aromatic DOM compounds.

\section{INTRODUCTION}

Marine dissolved organic matter (DOM) is one of the largest active carbon pools on Earth and, thus, an important component of the global carbon cycle. ${ }^{1}$ The Earth's continents are a major source of terrigenous DOM to the oceans, which is transported with other constituents such as iron $(\mathrm{Fe})$ via riverine and submarine groundwater inputs. Groundwaterbased fluxes, however, are not well constrained because before entering the coastal ocean, groundwater passes through a biogeochemically active environment, the subterranean estuary ${ }^{2}$ (STE). While DOM has been found to coagulate with Fe(III) (oxy)hydroxides at redox boundaries in other environments, $\mathrm{Fe}-\mathrm{DOM}$ coagulation processes in STEs have not yet been investigated, despite much already being known about $\mathrm{Fe}$ cycling in STEs. ${ }^{3-9}$ If $\mathrm{Fe}-\mathrm{DOM}$ coagulation is prominent in STEs, which are characteristic of sandy shores that cover "up to two-thirds of the world's ice-free coastlines", ${ }^{10}$ then such processes would be of global importance in terms of modulating the transport of terrigenous constituents from land to the ocean, with consequential implications on the global carbon cycle.

STEs are coastal aquifers where meteoric groundwater mixes with recirculating seawater. To date, no coherent database of the global coverage of STEs exists, but the occurrence of submarine groundwater discharge (SGD), the advective flux of terrestrial and marine groundwater into the ocean that originates from the STE, has been reported worldwide. ${ }^{11}$ It has been estimated that the annual discharge of freshwater via SGD amounts to $\sim 2400 \mathrm{~km}^{3}$ /year, with the majority of it passing through unconfined aquifers such as permeable beach sediments prior to entering the coastal ocean. ${ }^{11}$ Because SGD can be highly enriched in nutrients, its constituent fluxes are estimated to be on the same order of magnitude as that of global surface runoffs, even though the freshwater volume flux amounts to only $6-10 \%$ as compared to rivers. ${ }^{12}$ SGD is also a significant source of DOM to the coastal environment, as well as of $\mathrm{Fe}$, a redox active trace metal and an important micronutrient for primary productivity in marine sediments. $^{13-15}$

In STEs, changes in redox potential are expected to serve as a main control for the removal or mobilization of $\mathrm{Fe}$ and other nutrients. Chambers and Odum $^{16}$ first used the term iron curtain for an iron hydroxide precipitation zone on tidal freshwater marsh creekbanks, where reduced iron, $\mathrm{Fe}(\mathrm{II})$, from advectively discharged porewater was oxidized to $\mathrm{Fe}$ (III) upon coming into contact with the oxygenated surface waters of the tidal creeks and consequently scavenging dissolved phosphate.

\section{Received: July 19, 2016}

Revised: December 14, 2016

Accepted: December 15, 2016

Published: December 15, 2016 
Later, Charette ${ }^{3}$ applied the expression to describe ferric hydroxide precipitates at redox interfaces within the STE. This iron curtain may vary spatially and temporally, depending on tidal amplitudes and long-term sea level changes, and acts as a barrier for chemical species such as phosphate and barium. ${ }^{3,5,6}$

The iron curtain has mostly been investigated with regard to the retention of inorganic constituents from submarine groundwater; however, various studies have described oxidative $\mathrm{Fe}-\mathrm{DOM}$ coagulation at different redox gradients. Riedel et al., ${ }^{17}$ for instance, studied Fe-DOM coagulation in peat bog samples and found that highly aromatic, typically terrestrial DOM molecules are more likely to coagulate with iron than are aliphatic compounds typically found in aged marine DOM. Gomez-Saez et al. ${ }^{18}$ recently showed that iron from iron-rich hydrothermal vent fluids, as it coagulates with DOM, leads to a decrease in dissolved organic carbon (DOC) and changes in DOM molecular composition in the surrounding seawater. In addition to the molecular properties described by Riedel et al. ${ }^{17}$ and Gomez-Saez et al., ${ }^{18} \mathrm{Lv}$ et al. ${ }^{19}$ also reported an affinity of higher-molecular weight compounds $(>500 \mathrm{Da})$ for coagulation with a variety of iron oxyhydroxides. They revealed that the extent of DOM coagulation was related to the type of iron substrate, with amorphous ferrihydrites scavenging more DOM than other iron oxyhydroxide minerals.

In their studies of the organic geochemistry of advective porewater systems of the German Wadden Sea, Seidel et al. ${ }^{20,21}$ recently postulated that $\mathrm{Fe}-\mathrm{DOM}$ interactions had affected the observed molecular properties of DOM. However, to the best of our knowledge, no experimental data about the reactivity of DOM with iron within the STE exist, although STEs probably occur ubiquitously along coastal shorelines and may affect land-ocean fluxes of DOM and Fe on a global scale. In addition, dissolved Fe concentrations in the STE are often in the micromolar range, ${ }^{3,6,9,22}$ which are equal to or larger than normal DOC concentrations in STE porewaters, ${ }^{3,21}$ and DOM coagulation potentials of $50-80 \%$ can be achieved for $\mathrm{Fe} /$ DOM ratios between 0.8 and $1.2 .^{23}$ The iron curtain as a major biogeochemical barrier within the STE thus has the potential to modulate the global transport of terrigenous constituents from land to the ocean. Here, we hypothesize that the iron curtain affects the quality and quantity of advective porewater DOM fluxes from STEs into the coastal ocean by retaining specific molecular fractions of terrigenous DOM.

Fractionation of DOM can be investigated on a molecular level with new nontargeted analytical technologies, in particular ultra-high-resolution mass spectrometry using soft ionization [electrospray ionization Fourier transform ion cyclotron resonance mass spectrometry (ESI-FT-ICR-MS)]. Whereas traditional analytical methods target only small groups of compounds, ESI-FT-ICR-MS allows the identification of specific molecules on a broader scale. ${ }^{24,25}$ This method allowed researchers to determine molecular DOM fingerprints to track water masses, ${ }^{24}$ follow the molecular succession of microbial remineralization, ${ }^{26}$ and identify the molecular formulas of DOM subject to change under experimental conditions. ${ }^{17,27,28}$

We studied coagulation of iron with DOM from a set of porewater samples from the northern beach of Spiekeroog Island, where an STE is formed by the terrestrial freshwater lens and the tidally recirculating seawater. We characterized both noncoagulating and coagulating fractions of DOM by molecular analysis with ESI-FT-ICR-MS.

\section{EXPERIMENTAL SECTION}

Overview. We collected porewater samples from three different sites along a transect perpendicular to the shoreline and one seawater sample as a reference. The stations were chosen to yield representative samples from the STE with varying amounts of fresh groundwater and recirculating seawater, and oxic to anoxic conditions. We performed precipitation experiments with samples that contained $\mathrm{Fe}^{2+}$ at micromolar concentrations, either naturally or through addition of an $\mathrm{Fe}^{2+}$ spike. We characterized the DOM molecular composition of all samples before and after their exposure to oxygen and subsequent precipitation of $\mathrm{Fe}$ (III) (oxy)hydroxides, identifying both noncoagulating and coagulating DOM fractions. All samples were desalted via solid-phase extraction $^{29}$ prior to molecular analysis via ESI-FT-ICR-MS.

Study Site. Spiekeroog is one of the East Frisian Islands in the German North Sea and part of the UNESCO World Heritage area "Wadden Sea". Peat and clay layers within the sand dunes confine its precipitation-fed fresh water lens at a depth of $\sim 40 \mathrm{~m} .{ }^{30}$ Spiekeroog is exposed to a mesotidal regime (2-4 $\mathrm{m}$ tidal range). With its complex redox zonation, Spiekeroog has formerly proved to be a suitable sampling site for studies on the biogeochemistry of STEs. ${ }^{21,31-33}$ Previously, numerical models from Spiekeroog South Beach, a sheltered site facing the Wadden Sea, revealed that tidal pumping produced an upper saline plume (USP) with an $\sim 100 \mathrm{~m}$ lateral extension and an $\sim 20 \mathrm{~m}$ depth. ${ }^{21}$ Groundwater from the fresh water lens discharged near the low tide water line, forced to a narrow tube. ${ }^{21}$ The model data were backed up by in situ geochemical transects, which in addition indicated a complex redox zonation, for example, two Fe reduction zones associated with organic matter decomposition at the drift line as well as at the low tide water line (LWL). ${ }^{21}$ Transect data from a shallow subterranean estuary at Spiekeroog North Beach recently indicated the occurrence of a similar USP at this exposed beach site. $^{22}$ Both studies from the north and south shores of Spiekeroog have described the STE as a biogeochemical reactor: They showed a succession of denitrification and iron and manganese reduction zones along the groundwater flow path from land to sea. ${ }^{21,22}$ Analogous to the south beach, a transition zone in the north beach STE with high $\mathrm{Fe}^{2+}$ concentrations was described near the LWL. ${ }^{22}$ The zone spanned a width of approximately $150-200 \mathrm{~m}$ and was bordered by sharply decreasing porewater $\mathrm{Fe}^{2+}$ concentrations, probably because of oxidation processes forming $\mathrm{Fe}$ (III) (oxy)hydroxide precipitates. A more detailed study of the north beach circulation system, including a numerical model, is currently in revision. ${ }^{34}$ On the basis of these previous findings, samples were taken at the north beach site of the island, at $53^{\circ} 46^{\prime} \mathrm{N}, 07^{\circ} 43^{\prime} \mathrm{E}$, in the vicinity of Umweltzentrum Wittbülten. Our sampling beach very likely represents the redox and iron gradients that are typical of many STEs worldwide. $^{5,6,9}$

Sampling. Samples were collected on December 10, 2013. Sites were selected on the basis of ref 22 and a preliminary study in November 2013 (see the Supporting Information), in which concentrations of nutrients and $\mathrm{Fe}^{2+35}$ had been measured in porewaters over the range of the study site to define the $\mathrm{Fe}(\mathrm{II}) / \mathrm{Fe}(\mathrm{III})$ transition zone of the local STE. Sampling started at the LWL at low tide. Porewater (PW) samples were taken at three different sites along a transect perpendicular to the shoreline, with increasing distances from 


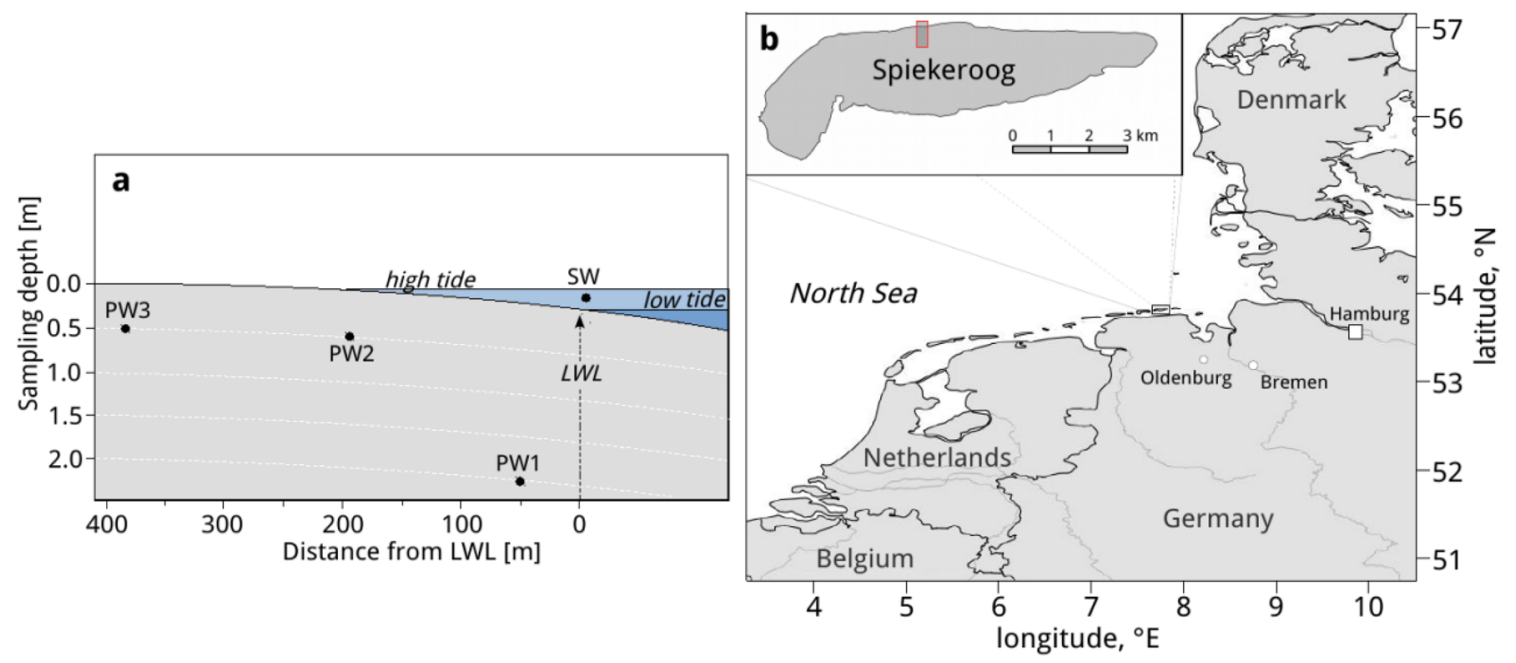

Figure 1. (a) Sampling scheme at $53^{\circ} 46^{\prime} \mathrm{N}, 07^{\circ} 43^{\prime} \mathrm{E}$, where LWL is the low tide water line on the day of sampling. (b) Spiekeroog Island, with the sampling area as shown in panel a marked with a red box. PW denotes sites of porewater sampling and SW sites of seawater sampling.

the LWL toward the sand dunes (Figure 1): PW1-PW3, with distances from the LWL of 100, 250, and $450 \mathrm{~m}$, respectively. PW1 and PW2 were located within the intertidal zone; PW1 was closest to the LWL and PW2 at the edge of the intertidal zone. PW3 was the most landward site and located outside the tidal zone, $\sim 50 \mathrm{~m}$ from the beginning of the foredune belt colonized by marram grass. Two seawater samples (SW) were taken from the surf zone during high tide.

At each of the three beach sites, porewater was sampled at two spots less than $1 \mathrm{~m}$ apart. Viton tubes were attached to stainless steel push point samplers placed into the sediments at a depth of $0.5-2 \mathrm{~m}$. At each spot prior to DOM sampling, small volumes of porewater were first sampled with a polyethylene syringe to determine salinity and $\mathrm{Fe}^{2+}$ concentrations. Salinity was measured with a standard Tetra-Con 925 Multi 3430 (WTW) conductivity measuring cell, and $\mathrm{Fe}^{2+}$ was detected by adding $1 \mathrm{~mL}$ of porewater to $1.5 \mathrm{~mL}$ clear safe-lock tubes (Eppendorf) containing $100 \mu \mathrm{L}$ of a ferrozine solution. ${ }^{35}$ Iron concentrations were then estimated in the field by visually comparing the emerging color from the ferrozine reaction with a color table. More precise $\mathrm{Fe}^{2+}$ determination was performed later in the laboratory (see below). Afterward, $2 \mathrm{~L}$ of porewater was taken from the selected spots by applying a gentle vacuum with a hand pump. The samples passed through an inline filter (a $3.0 \mu \mathrm{m}$ Millipore Isopore polycarbonate membrane filter on top of a $0.2 \mu \mathrm{m}$ Pall polyethersulfon membrane filter, both 47 $\mathrm{mm}$ in diameter) into acid-washed $2 \mathrm{~L}$ polycarbonate (PC) bottles (Nalgene). The bottles were fitted with vacuum caps and PC two-way valves and had been flushed and filled with Ar gas to a slight overpressure before sampling to prevent oxygen contamination and subsequent uncontrolled Fe(III) precipitation. The SW samples were also collected in acid-washed $2 \mathrm{~L}$ PC bottles but filtered approximately $2 \mathrm{~h}$ later back in the laboratory by vacuum as described above for PW1-PW3. After the first round of filtration, subsamples for DOC and trace metals were extracted from the PC bottles with acid-washed syringes attached to the vacuum valves. All subsamples were acidified with $\mathrm{HCl}$ (Merck, suprapur) to $\mathrm{pH} 2$ and stored in acid-washed HDPE bottles at $4{ }^{\circ} \mathrm{C}$ in the dark. All PC bottles were soaked in $0.14 \mathrm{M}$ nitric acid $\left(\mathrm{HNO}_{3}\right.$ p.a., Carl Roth, $1 \%$ in ultrapure water) and $0.01 \mathrm{M}$ hydrochloric acid (suprapur) for 1 week each and rinsed repeatedly with ultrapure water prior to use. All other nonglass material (filter membranes, filter holders, tubing, sampling bottle caps, etc.) were soaked in $0.14 \mathrm{M} \mathrm{HNO}_{3}$ (p.a.) for several weeks and rinsed repeatedly with ultrapure water before being used. Samples for analyses of trace metals, DOC, and solid-phase extraction of DOM were acidified to a final concentration of $0.01 \mathrm{M} \mathrm{HCl}$ (suprapur).

Precipitation Experiments. Controls (one per site). To prevent any $\mathrm{Fe}$ in solution from precipitating, the filtered control samples in the $\mathrm{PC}$ bottles were acidified in situ to $\mathrm{pH} 2$ with $\mathrm{HCl}$. This is also the $\mathrm{pH}$ necessary for solid-phase extraction as described below. ${ }^{29}$ The SW samples were filtered in the laboratory and thereafter split into two sets, with one of them being acidified to serve as a control and the other being prepared as a treatment sample as follows.

Treatment Samples (one per site). After all samples had been brought back to the laboratory, $\mathrm{Fe}^{2+}$ was roughly quantified in the ferrozine subsamples by visual comparison with an $\mathrm{Fe}^{2+}$-ferrozine calibration series $(5-100 \mu \mathrm{M})$ prepared prior to sampling. In the porewater closest to the LWL (PW1), natural $\mathrm{Fe}^{2+}$ was present as indicated by the in situ ferrozine test; in all other samples, no visible $\mathrm{Fe}$ (II)-ferrozine coloration was found. $\mathrm{Fe}^{2+}$ from an $\mathrm{FeCl}_{2}$ (EMSURE, Merck) spike solution enriched with a suprapur hydroxylamine hydrochloride solution to prevent any $\mathrm{Fe}^{2+}$ from oxidizing $\left(\mathrm{HONH}_{2} \cdot \mathrm{HCl}\right.$, Merck) was then added to all treatment samples of PW2, PW3, and SW in amounts approximating the concentrations of those estimated in PW1 $(\sim 80 \mu \mathrm{M})$. The hydroxylamine hydrochloride concentration was just high enough to keep the spike in solution. After a short exposure to atmospheric oxygen, the bottles were capped, shaken, and left standing for $24 \mathrm{~h}$. The samples were then shaken again, and each of the treatment samples was filtered again (through an inline filter such as in the field), split into four acid-washed $2 \mathrm{~L} \mathrm{PC}$ bottles, and acidified to $\mathrm{pH} 2$ with suprapur $\mathrm{HCl}$. These four replicates are hereafter termed filtrate samples. One filter served for the filtration of two replicates. After filtration, all filters were rinsed and desalted with ultrapure water and stored at $4{ }^{\circ} \mathrm{C}$. The precipitates were later gently dissolved in $0.01 \mathrm{M} \mathrm{HCl}(\mathrm{pH} 2)$ and are termed precipitate samples.

Analysis of DOC, Nutrient, Fe, and Mn. DOC concentrations were measured on a Shimadzu (TOC-VCPH and TNM-1) analyzer, using high-temperature catalytic 
Table 1. Biogeochemical Characteristics of the Sampling Sites

\begin{tabular}{|c|c|c|c|c|c|c|c|c|c|c|c|c|}
\hline site & & $\begin{array}{l}\text { latitude } \\
07^{\circ} 43^{\prime}\end{array}$ & $\begin{array}{c}\text { longitude } \\
53^{\circ} 46^{\prime}\end{array}$ & $\begin{array}{c}\text { depth } \\
(\mathrm{m})\end{array}$ & Sal & $\begin{array}{c}\mathrm{DOC}^{a} \\
(\mu \mathrm{M})\end{array}$ & $\begin{array}{l}\mathrm{Fe}^{2+b} \\
(\mu \mathrm{M})\end{array}$ & $\begin{array}{l}\mathrm{Fe}_{\text {tot }}{ }^{c} \\
(\mu \mathrm{M})\end{array}$ & $\begin{array}{l}\mathrm{Mn}^{c} \\
(\mu \mathrm{M})\end{array}$ & $\begin{array}{l}\mathrm{NH}_{4} \\
(\mu \mathrm{M})\end{array}$ & $\begin{array}{l}\mathrm{NO}_{x} \\
(\mu \mathrm{M})\end{array}$ & $\begin{array}{c}\mathrm{PO}_{4} \\
(\mu \mathrm{M})\end{array}$ \\
\hline \multirow[t]{3}{*}{ SW } & control & & & surf zone & & 193 & $\mathrm{nd}^{d}$ & $0.09^{e}$ & $0.04^{e}$ & 12.1 & 15.3 & 0.3 \\
\hline & pretreatment & - & - & & 30.4 & 297 & $\mathrm{nd}^{d}$ & - & - & & & \\
\hline & post-treatment & & & & & 215 & - & $0.09^{e}$ & $0.04^{e}$ & - & - & - \\
\hline \multirow[t]{3}{*}{ PW1 } & control & & & 2 & & 284 & 37.54 & 67.9 & 15.65 & 57.1 & $\mathrm{nd}^{d}$ & 2.8 \\
\hline & pretreatment & 41.3 & 57.6 & 2 & 29.7 & 132 & 80.44 & - & - & 17.9 & $\mathrm{nd}^{d}$ & 3.3 \\
\hline & post-treatment & & & & & 180 & - & $0.09^{e}$ & 5.89 & - & - & - \\
\hline \multirow[t]{3}{*}{ PW2 } & control & & & 0.5 & & 160 & 0.27 & 0.22 & $0.04^{e}$ & $\mathrm{nd}^{d}$ & 46.8 & 4.9 \\
\hline & pretreatment & 37.4 & 53.2 & 0.5 & 24.0 & 182 & $\mathrm{nd}^{d}$ & - & - & 1.4 & 47.4 & 21.1 \\
\hline & post-treatment & & & & & 190 & - & $0.09^{e}$ & $0.04^{e}$ & - & - & - \\
\hline \multirow[t]{3}{*}{ PW3 } & control & & & 0.5 & & 260 & $\mathrm{nd}^{d}$ & $0.09^{e}$ & $0.04^{e}$ & $\mathrm{nd}^{d}$ & 59.0 & 3.6 \\
\hline & pretreatment & 33.6 & 47 & 0.5 & 9.0 & 235 & $\mathrm{nd}^{d}$ & - & - & $\mathrm{nd}^{d}$ & 27.2 & 4.6 \\
\hline & post-treatment & & & & & 137 & - & $0.04^{e}$ & $0.04^{e}$ & - & - & - \\
\hline
\end{tabular}

${ }^{a}$ Control and pretreatment: after the first filtration, mean values of three injections. Post-treatment: after coagulation and the second filtration, mean values of duplicate samples, three injections each. ${ }^{b}$ Natural reduced iron concentration according to the ferrozine test, ${ }^{35}$ as measured at the sampling spot prior to taking the ESI-FT-ICR-MS samples. ${ }^{c}$ Total dissolved iron or manganese, as measured via ICP-MS directly from the ESI-FT-ICR-MS samples, after coagulation and filtration of the treatment samples. PW1 treatment samples were not measured via ICP-MS because of their high Fe and $\mathrm{Mn}$ concentrations; thus, ICP-OES results are given. ${ }^{d}$ Not detected (below the detection limit). ${ }^{e}$ At the threshold of the detection limit.

oxidation, against a calibration series and a deep sea reference standard provided by D. Hansell (University of Miami, Miami, FL). The samples were measured via a low-volume handinjection method. ${ }^{36}$ Concentrations of nutrients [sum of nitrate and nitrite $\left(\mathrm{NO}_{x}\right)$, ammonium, and phosphate] and $\mathrm{Fe}^{2+}$ from ferrozine treatments of the porewater samples were measured by UV/vis microplate spectroscopy (Multiscan Spectrum, Thermo Scientific) at the ICBM Microbiogeochemistry Laboratory at the University of Oldenburg (Oldenburg, Germany). Nutrients were measured with a method modified from refs 37 and 38 , and $\mathrm{Fe}^{2+}$ was measured according to ref 35 . Total $\mathrm{Fe}$ and $\mathrm{Mn}$ were measured by inductively coupled plasma optical emission spectrometry (ICP-OES) (iCAP 6000, Thermo Scientific) coupled with an argon humidifier ( $T$ $2100 \mathrm{BR})$; resultant data were analyzed with iTEVA software. Calibration was performed with NIST traceable standard solutions and verified using SLEW-3 as reference material. ${ }^{33}$

Solid-Phase Extraction. For ESI-FT-ICR-MS analysis, samples must be salt-free and concentrated to a carbon concentration of $>10 \mathrm{mg} \mathrm{L}^{-1}$. All samples were thus extracted via solid-phase extraction (SPE) according to the method described in ref 29; $1 \mathrm{~g}$ Varian Bond Elut PPL cartridges were used for extraction. Their solid phase is a modified styrenedivinylbenzene (SDBV) polymer that is capable of also retaining some polar analytes, including phenols. ${ }^{29,39}$ Prior to use, the cartridges were soaked with methanol (UPLC/MS grade, Biosolve BV) overnight and rinsed twice with ultrapure water, twice with methanol, and twice with $0.01 \mathrm{M} \mathrm{HCl}$ (suprapur). All samples were acidified to $\mathrm{pH} 2$ with $\mathrm{HCl}$ prior to extraction to prevent $\mathrm{Fe}$ (III) precipitation outside of the control of the experimental setup and to increase the extraction efficiency for the organic acids and phenols that are present. After the samples had been passed over the SPE resin, the cartridges were rinsed with $100 \mathrm{~mL}$ of $0.01 \mathrm{M} \mathrm{HCl}$ and dried with $\mathrm{Ar}$ gas. The absorbed DOM samples on the cartridges were then immediately eluted with $6 \mathrm{~mL}$ of methanol into precombusted amber glass vials. The eluted extracts were stored in the dark at $-18{ }^{\circ} \mathrm{C}$. Prior to analysis by ESI-FT-ICRMS, all extracts were diluted with ultrapure water and methanol to yield a $15 \mathrm{ppm}$ solution in a $1 / 1(\mathrm{v} / \mathrm{v})$ methanol/water mixture. Extracts with lower DOC concentrations, such as the precipitate samples, were concentrated by evaporation and redissolved with a $1 / 1$ methanol/water mixture. Extraction efficiencies were calculated after determining DOC concentrations in both the original water samples and the extracts (after complete evaporation of the methanol and redissolution in ultrapure water) and were $43 \pm 7 \%$ for all filtrate and control samples and $47 \pm 12 \%$ for all precipitate samples.

Molecular Analysis. Samples were measured on a Bruker Solarix ESI-FT-ICR-MS instrument (Bruker Daltonik GmbH, Bremen, Germany), equipped with a $15 \mathrm{~T}$ magnet system. All samples were analyzed in negative electrospray ionization (ESI, Bruker Apollo II) mode. All instrument settings and data processing approaches, including molecular formula assignments, are described in detail in ref 21 . All filtrate and control samples were measured over the course of 2 days in randomly mixed order. To test the reproducibility and stability of the ESIFT-ICR-MS analysis, a DOM extract of North Equatorial Pacific Intermediate Water (NEqPIW) was used as a reference sample. This sample is an in-house reference material for aged, marine DOM. $^{40}$ On the basis of the suggestions made by Stenson et al. ${ }^{41}$ and Koch et al., ${ }^{42}$ we used an element setting of ${ }^{12} \mathrm{C}_{1-130}{ }^{1} \mathrm{H}_{1-200}{ }^{16} \mathrm{O}_{1-50}{ }^{14} \mathrm{~N}_{1-50} 0{ }^{14} \mathrm{~N}_{0-4}{ }^{32} \mathrm{~S}_{0-2}$ for molecular formula assignments. The double bond equivalence (DBE) was determined using the method described by Stenson et al., ${ }^{41}$ and the aromaticity index was determined in its modified version using the method described by Koch and Dittmar ${ }^{43,44}$ (AImod).

Statistics. After molecular formulas were assigned, data were further statistically analyzed by using the software package "R" (version 3.1.1, 2014-04-10). To test for differences in molecular composition between filtrate and control samples, a Mann-Whitney-U test $(\alpha=0.05)$ was applied, the nonparametric version of the $t$ test for the determination of significant differences between two data sets with non-normally distributed residuals. The molecular formulas driving those differences were then further investigated. The precipitate samples were not included in the statistical analyses described above but were finally used to compare the presence and absence of molecular formulas between filtrate and precipitate fractions. 
Table 2. Molecular Characterization of the DOM Samples As Determined by ESI-FT-ICR-MS ${ }^{a}$

\begin{tabular}{|c|c|c|c|c|c|}
\hline & control & $\begin{array}{l}\text { treatment (present in } \\
\text { filtrate) })^{b}\end{array}$ & $\begin{array}{l}\text { treatment (absent from } \\
\text { filtrate })^{b}\end{array}$ & $\begin{array}{l}\text { treatment (present in } \\
\text { precipitate) }\end{array}$ & $\mathrm{NEqPIW}^{d}$ \\
\hline total no. of molecules & 2066 & 1829 & 217 & 114 & 1378 \\
\hline mean mass $(\mathrm{Da})$ & 380 & 395 & 470 & 409 & 406 \\
\hline average formula & $\mathrm{C}_{18.5} \mathrm{H}_{21.1} \mathrm{O}_{8.2} \mathrm{~N}_{0.1} \mathrm{~S}_{0.3}$ & $\mathrm{C}_{18.2} \mathrm{H}_{21.2} \mathrm{O}_{7.8} \mathrm{~N}_{0.1} \mathrm{~S}_{0.3}$ & $\mathrm{C}_{21.8} \mathrm{H}_{20.8} \mathrm{O}_{11.8} \mathrm{~N}_{0.0} \mathrm{~S}_{0.0}$ & $\mathrm{C}_{19.5} \mathrm{H}_{17.5} \mathrm{O}_{9.9} \mathrm{~N}_{0.0} \mathrm{~S}_{0.0}$ & $\mathrm{C}_{19.9} \mathrm{H}_{24.0} \mathrm{O}_{8.8} \mathrm{~N}_{0.0} \mathrm{~S}_{0.3}$ \\
\hline average $\mathrm{H} / \mathrm{C}$ atom ratio & 1.1 & 1.2 & 0.9 & 0.9 & 1.2 \\
\hline average $\mathrm{O} / \mathrm{C}$ atom ratio & 0.4 & 0.4 & 0.5 & 0.5 & 0.4 \\
\hline${\text { average } \text { AImod }^{e}}^{2}$ & 0.4 & 0.4 & 0.4 & 0.5 & 0.3 \\
\hline average $\mathrm{DBE}^{f}$ & 9.1 & 8.8 & 12.4 & 11.7 & 9.0 \\
\hline $\begin{array}{l}\text { percentage of combustion-derived } \\
\text { polycyclic aromates (PCAs) (AImod } \\
>0.66 \text { ) }\end{array}$ & 10.0 & 10.1 & 9.7 & 12.4 & 3.1 \\
\hline PCAs smaller than $\mathrm{C}_{15}$ & 7.0 & 7.4 & 3.7 & 7.0 & 2.4 \\
\hline PCAs larger than or equal to $C_{15}$ & 3.0 & 2.6 & 6.0 & 5.3 & 0.7 \\
\hline PCAs rich in $\mathrm{O}(\mathrm{O} / \mathrm{C}>0.5)$ & 0.8 & 1.0 & 0.5 & 0.9 & 0.0 \\
\hline PCAs poor in $\mathrm{O}(\mathrm{O} / \mathrm{C} \leq 0.5)$ & 9.1 & 9.1 & 9.2 & 11.5 & 3.1 \\
\hline $\begin{array}{l}\text { percentage of polyphenols }(0.66 \geq \\
\text { AImod }>0.5)\end{array}$ & 19.2 & 17.5 & 30.9 & 38.0 & 14.3 \\
\hline polyphenols rich in $\mathrm{O}(\mathrm{O} / \mathrm{C}>0.5)$ & 4.6 & 3.9 & 11.5 & 9.7 & 1.4 \\
\hline polyphenols poor in $\mathrm{O}(\mathrm{O} / \mathrm{C} \leq 0.5)$ & 14.6 & 13.7 & 19.4 & 28.3 & 12.9 \\
\hline $\begin{array}{l}\text { percentage of highly unsaturated } \\
\text { molecules (HU) }\end{array}$ & 59.7 & 60.0 & 59.4 & 49.6 & 72.8 \\
\hline $\mathrm{HU}$ rich in $\mathrm{O}(\mathrm{O} / \mathrm{C}>0.5)$ & 24.4 & 21.9 & 48.8 & 37.2 & 28.0 \\
\hline $\mathrm{HU}$ poor in $\mathrm{O}(\mathrm{O} / \mathrm{C} \leq 0.5)$ & 35.3 & 38.1 & 10.6 & 12.4 & 44.8 \\
\hline
\end{tabular}

\section{RESULTS}

General Biogeochemical Characteristics of the STE. The studied system was highly heterogeneous (Table 1). Nutrient and DOC concentrations varied substantially within only $1 \mathrm{~m}$ sampling distance for control and treatment samples from the same station. In particular, DOC displayed no specific trend, as it varied more between close locations at a given station than between stations. In some of the experiments (PW1 and PW2), bulk DOC concentrations were higher after than before the precipitation treatments. We excluded these DOC data from further consideration because of the risk of contamination with volatile organics. The other porewater constituents showed a clear trend among sites. For example, the more landward PW2 and PW3 stations were enriched with $\mathrm{NO}_{x}$, whereas station PW1 was clearly located in an iron reduction zone, with $\mathrm{NH}_{4}$ being the dominant form of dissolved inorganic nitrogen. Total dissolved $\mathrm{Fe}$ was completely removed from the filtrate samples after the second filtration step, while we found precipitated $\mathrm{Fe}$ (III) (oxy)hydroxides in the precipitate samples. Thus, we investigated the molecular composition of solid-phase-extracted DOM in the $\mathrm{Fe}(\mathrm{III})$ (oxy)hydroxide precipitates, as well as in the filtered permeate, to track experimentally induced changes not evident in bulk DOC data.

Molecular Characteristics of DOM. We identified 2066 molecular formulas, representing 34\% of all 6015 molecular masses detected by ESI-FT-ICR-MS. Unassigned masses are isotopologues of assigned molecular formulas or contain combinations of elements not considered in this study. By Mann-Whitney-U testing on all 6015 masses, we found that 423 compounds were responsible for significant differences between filtrate and control samples $(p<0.05) ; 267$ of these 423 compounds were missing or had significantly lower intensities in the mass spectra of the filtrate samples, suggesting that they coagulated with iron and were filtered out from the filtrate samples. To 217 of these 267 detected masses (4\% of all 6015 compounds and $11 \%$ of all 2066 molecularly described compounds) were we able to assign molecular formulas. In the precipitate, 114 of these 217 missing compounds in the filtrate could be detected ( $2 \%$ of all 6015 compounds and $6 \%$ of all 2066 molecularly described compounds). It should be noted that we were not able to fully redissolve the precipitate from the filter holders by the acidification processing step.

We identified $\mathrm{C}_{18.5} \mathrm{H}_{21.1} \mathrm{O}_{8.2} \mathrm{~N}_{0.1} \mathrm{~S}_{0.3}$ as the average formula for all molecules present in the control samples and $\mathrm{C}_{21.8} \mathrm{H}_{20.8} \mathrm{O}_{11.8} \mathrm{~N}_{0.0} \mathrm{~S}_{0.0}$ for all molecules that were missing in the filtrate residual solution of the treatment, indicating that they had been removed during precipitation. $\mathrm{C}_{18.2} \mathrm{H}_{21.2} \mathrm{O}_{7.8} \mathrm{~N}_{0.1} \mathrm{~S}_{0.3}$ is the average formula for all compounds that remained in the residual filtrate after coagulation. The reference deep sea standard, NEqPIW, in comparison, had a molecular formula of $\mathrm{C}_{19.9} \mathrm{H}_{24.0} \mathrm{O}_{8.8} \mathrm{~N}_{0.0} \mathrm{~S}_{0.3}$ (Table 2).

Molecular Categories. We found that iron coagulation specifically affected large molecules with a relatively high oxygen content. The mean mass and oxygen content of the molecules that were removed from the filtrate samples (470 Da, $12 \mathrm{O})$ were substantially higher than the mean mass of all described molecules as found in the control samples $(380 \mathrm{Da}, 8$ O) and the residual filtrate (395 Da, $8 \mathrm{O})$. DBE was much higher for the coagulated molecules (12) than for molecules in the control samples and the residual filtrate (both 9), suggesting a preferential coagulation of molecules with a higher content of unsaturated fractions. As another indicator for rather unsaturated, oxygenated molecules undergoing coagulation, coagulated molecules tended to have a relatively high $\mathrm{O} / \mathrm{C}$ and low $\mathrm{H} / \mathrm{C}$ ratio ( 0.5 and 0.9 , respectively) as compared to all 
identified molecules in the controls ( 0.4 and 1.1, respectively) and residual filtrates (0.4 and 1.2, respectively) (Figure 2).

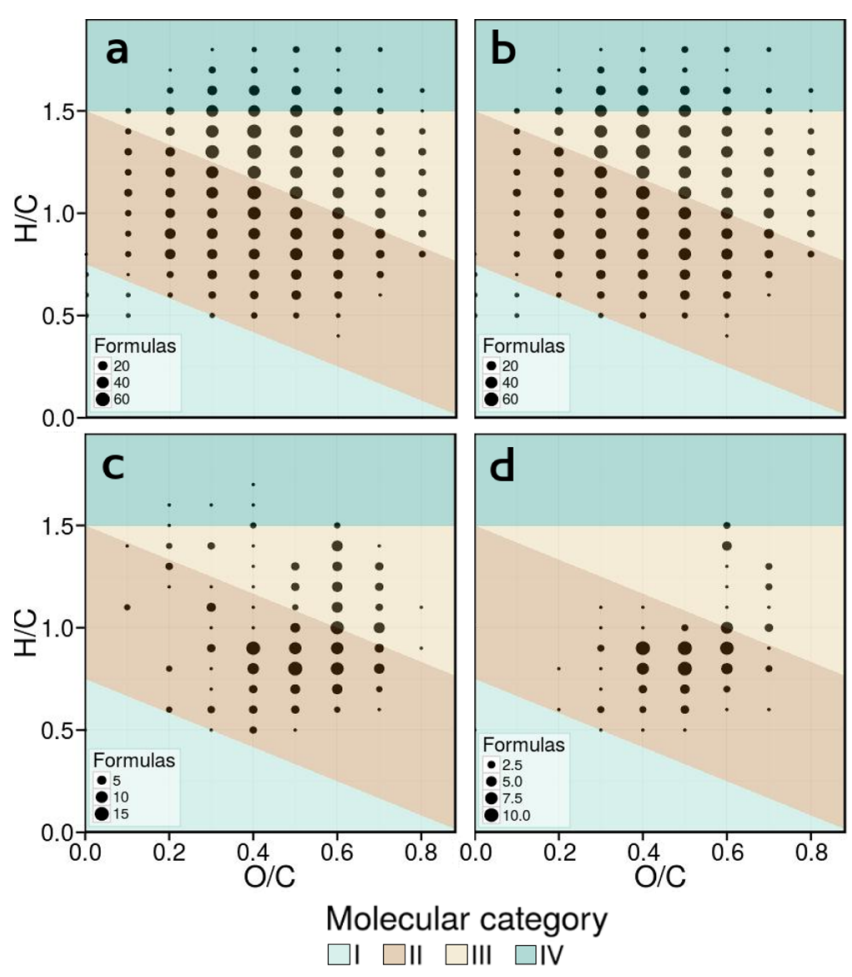

Figure 2. Abundance frequency plots of molecular formulas in categories of $\mathrm{O} / \mathrm{C}$ and $\mathrm{H} / \mathrm{C}$ element ratios (Van Krevelen diagrams), showing the distribution of all detected molecular formulas in the respective sample: (a) present in all controls, (b) retained in the filtrates, (c) with relative intensities in the filtrate samples statistically significantly lower than those in the control samples, i.e., thought to have coagulated with iron, and (d) the coagulating molecules from panel $\mathrm{c}$ that were also detected in the precipitate samples. All four diagrams include all sampling sites. The color code in the background shows the different molecular categories according to Šantl Temkiv et al.: ${ }^{45}$ (I) combustion-derived polycyclic aromates (PCAs), (II) soilderived polyphenols and PCAs with aliphatic chains, (III) soil-derived "humics" (i.e., phenolic and highly unsaturated compounds), and (IV) unsaturated aliphatic compounds.

\section{DISCUSSION}

Molecular Selectivity of Coagulation. Our findings of preferential coagulation of large, oxidized, aromatic molecules with a high content of unsaturated fractions are in general agreement with previous reports from a variety of different environmental and experimental setups. ${ }^{17-19}$ Contrary to Gomez-Saez et al., ${ }^{18}$ who, in a similar experiment in a hydrothermal vent system, found a selective enrichment of sulfuric groups in their iron-DOM coagulate precipitate samples, we did not find preferential coagulation of nitric or sulfuric DOM; they were also not found missing in the filtrate or present in the precipitate samples. It should be noted though that Gomez-Saez et al. ${ }^{18}$ worked with samples naturally much higher in organic sulfur, and many terrigenous DOM fractions may have already been removed as they worked with seawater samples, which potentially leaves less competition for Fe oxide surfaces from remaining other (marine) organic matter fractions. We found no general preferential coagulation of molecules classified as combustion-derived ("black carbon") or highly saturated compounds, but it was the large, oxidized fraction within these compound groups that coagulated. In general, compounds that are characteristic of terrigenous DOM (categories II and III in Figure 2) preferentially coagulated. No evidence of the precipitation of compounds that share molecular formulas with sugars, peptides, or aliphatic molecules was found.

Like any analytical technique, SPE combined with FT-ICRMS has its analytical window. Even though the analytical window of this combination of techniques is unsurpassed for molecular DOM analysis, not all compounds are detectable. In a study by Hawkes et al., ${ }^{39}$ experimental modifications of DOM moved a molecularly defined fraction out of the analytical window, which was clear evidence of substantial molecular modifications. We do not rule out this possibility in our study. Several past studies (e.g., Seidel et al. ${ }^{46}$ ) have, however, shown that our approach is not selective toward marine or terrigenous (polyphenolic) compounds. Our extraction efficiencies are at the lower reported end for PPL-SPE but are still within the range of similar samples. Most importantly, there was no systematic difference between types of samples.

Land-Ocean Trends and STE Heterogeneity. Our findings for DOM fractions prone to coagulation with iron are consistent with previous descriptions from peat-bog samples by Riedel et al. ${ }^{17}$ We additionally show that these processes of preferential coagulation of terrigenous DOM work in terrestrial and marine environments. On the basis of our experimental setup, we were able to estimate the "coagulation potential" of all studied porewater samples at each sampling site. We achieved this by calculating the cumulative difference of relative molecular abundances between control and filtrate samples for each site. To present our data, we describe three molecular categories that coagulated most with iron: group II and III according to Šantl Temkiv et al. ${ }^{45}$ and all molecules with an $\mathrm{O} / \mathrm{C}$ ratio of $>0.35$ and a $\mathrm{H} / \mathrm{C}$ ratio of $<1.0$ (Figures 2 and $3)$. Overall, the extent of coagulation decreased along the studied transect from land to sea (Figure 3). We suggest that, as DOM from terrestrial sources is transported through the STE, fractions more prone to iron coagulation (such as polyphenols, PCAs with aliphatic chains, and phenolic and highly unsaturated compounds) precipitate with iron, so that the extent of coagulation overall decreases with increasing distance from land to sea.

STEs are highly heterogeneous systems, and the observed land-ocean trends in the extent of coagulation contribute in a systematic way to the apparent heterogeneity of the STE. Compositional differences in DOM from the various groundwater end members may have contributed to the observed trend. Further, the retention of metal-sensitive DOM fractions in the STE is intrinsically linked to sediment redox chemistry, which is not directly dependent on salinity. For example, Seidel et $\mathrm{al}^{21}$ found highly aromatic, terrigenous DOM in an intertidal porewater seepage zone on the southern shore of Spiekeroog, downstream of several iron oxidation-reduction zones in the STE. They suggested on the basis of their findings that FeDOM coagulation in the STE is a reversible process. Similarly, concomitant dissolution of $\mathrm{Fe}$ and DOC under anoxic conditions and fast subsequent flocculation after the reestablishment of oxic conditions were reported from incubation studies with boreal lake sediments. ${ }^{47}$ Therefore, movements of the freshwater-saltwater boundary over tidal, seasonal, or even geological time scales, which influence advective flow rates and the supply of organic matter for microbial processes in the 


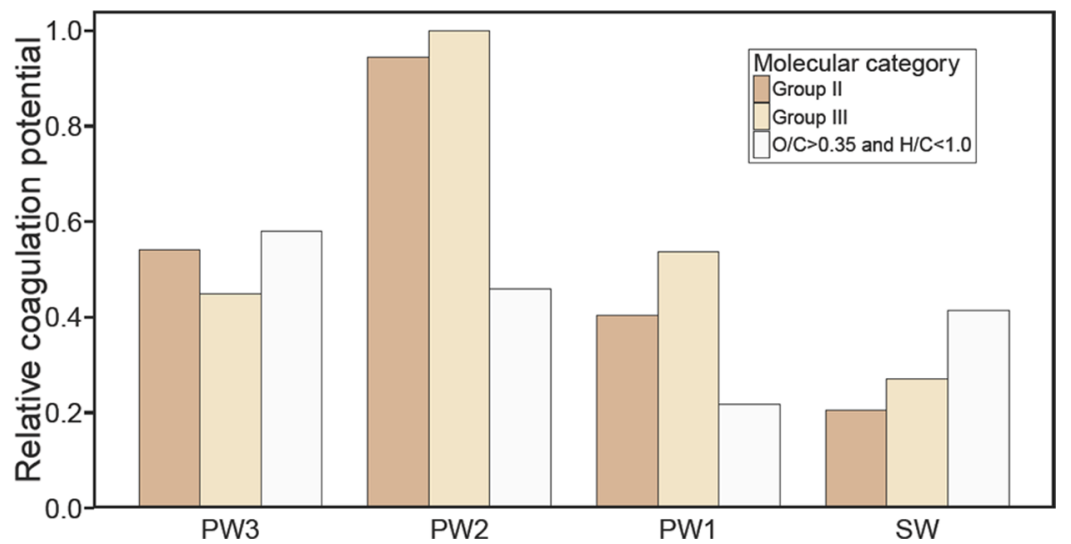

Figure 3. Relative coagulation potential for the four different sampling sites, from the dunes (PW3) to the sea (SW). Dark brown bars show data for group II, soil-derived polyphenols and PCAs with aliphatic chains. Light brown bars show data for group III, soil-derived "humics", i.e., polyphenolic and highly unsaturated compounds, both as according to Šantl Temkiv et al. ${ }^{45}$ Light gray bars show data for samples with an O/C of $>0.35$ and a $\mathrm{H} /$ $\mathrm{C}$ of $<1.0$, i.e., large unsaturated molecules with a high oxygen content. The coagulation potential is calculated as the cumulative difference in relative molecular abundances (ESI-FT-ICR-MS signal intensities) between control and filtrate samples per sampling site, each shown relative to the highest potential found (i.e., PW2 group III).

$\mathrm{STE},{ }^{8,48}$ will also impact the dynamics of the iron curtain. For example, microbial reduction of iron, triggered by the supply of fresh, labile marine DOM from a spring bloom, could trigger the release of older, more aromatic DOM of meteoric origin into the coastal water column. We therefore hypothesize that the STE has the potential to act as intermediate storage, ${ }^{17}$ rather than only as a net sink, for terrigenous aromatic DOM compounds.

Implications. In this study, we showed that Fe-DOM coagulation, a process previously studied on the molecular level only in terrestrial and hydrothermal vent systems, occurs at coastal beach sites, potentially on a global scale. We found preferential coagulation of $\mathrm{Fe}$ with DOM of a molecular composition typical for soil-derived DOM, such as highly oxidized polyphenols.

The discovery of Fe-DOM coagulation in STEs potentially has major implications as STEs occur globally, and DOM is an essential component of the global carbon cycle. Our study supports the hypothesis of the iron curtain selectively modulating the advective groundwater fluxes of organic carbon from land to sea. Whereas ESI-FT-ICR-MS allows for detailed qualitative molecular analyses, the quantitative relevance of iron-DOM coagulation in STEs should be further investigated by additional techniques; for example, terrestrial marker compounds can be used for quantification with liquid chromatography, or the sediments can be leached to quantify the attached DOM.

As we do not know the time scale on which coagulated DOM is buried in coastal and shelf sediments, we cannot determine if STEs act as a temporal storage or an effective longterm sink for terrigenous DOM. In this study, we investigated a shallow STE. Deep STEs might have different dynamics such as longer residence times, which may influence the forms of DOM that can potentially coagulate and the ultimate fate of sedimentary bound DOM. The role of iron in the preservation of organic matter in sediments is well-known. ${ }^{49}$ Our study indicates that terrigenous DOM may also be trapped and preserved in the "rusty carbon sink" from land to ocean. Many open questions about the global relevance of this process and the relevant time scales involved for burial and potential remobilization remain and should be the focus of future studies.

\section{ASSOCIATED CONTENT}

\section{Supporting Information}

The Supporting Information is available free of charge on the ACS Publications website at DOI: 10.1021/acs.est.6b03608.

Data from a preliminary study to define the sampling site (PDF)

\section{AUTHOR INFORMATION}

\section{Corresponding Authors}

*Phone: +46 18471 6568. E-mail: liannika@alumni.ethz.ch. *Phone: +49 441798 3348. E-mail: hannelore.waska@unioldenburg.de.

\section{ORCID}

Annika Linkhorst: 0000-0002-3609-5107

\section{Present Address}

${ }^{\S}$ A.L.: Department of Ecology and Genetics/Limnology, Uppsala University, 75236 Uppsala, Sweden.

\section{Notes}

The authors declare no competing financial interest.

\section{ACKNOWLEDGMENTS}

We thank Anja Reckhardt, Matthias Friebe, and Kevin Obermann for valuable field assistance, Katrin Klaproth, Matthias Friebe, Eleonore Gründken, and Ina Ulber for technical laboratory assistance, and Heike Simon for hand injection of the DOC samples. We are grateful to the associate editor and three anonymous reviewers for their constructive comments that significantly improved the manuscript. We gratefully acknowledge funding by the Deutsche Forschungsgemeinschaft (DFG, Eigene Stelle for H.W., WA3067/1-2) and an Erasmus student placement scholarship as provided to A.L. by ETH Zurich. A.L. acknowledges additional funding from the European Research Council under the European Union's Seventh Framework Programme (FP7/2007-2013)/ERC Grant Agreement $n^{\circ}$ 336642. We further thank Umweltzentrum Wittbülten on Spiekeroog Island and the microbiogeochemistry group at ICBM Oldenburg for providing their facilities. 


\section{REFERENCES}

(1) Ridgwell, A.; Arndt, S. Why Dissolved Organics Matter: DOC in Ancient Oceans and Past Climate Change. In Biogeochemistry of Marine Dissolved Organic Matter, 2nd ed.; Hansell, D. A., Carlson, C. A., Eds.; Academic Press: New York, 2015; pp 1-20.

(2) Moore, W. S. The subterranean estuary: a reaction zone of ground water and sea water. Mar. Chem. 1999, 65 (1-2), 111-125.

(3) Charette, M. A.; Sholkovitz, E. R. Oxidative precipitation of groundwater-derived ferrous iron in the subterranean estuary of a coastal bay. Geophys. Res. Lett. 2002, 29 (10), 85-1-85-4.

(4) Charette, M. A.; Sholkovitz, E. R; Hansel, C. M. Trace element cycling in a subterranean estuary: Part 1 . Geochemistry of the permeable sediments. Geochim. Cosmochim. Acta 2005, 69 (8), 20952109.

(5) Charette, M. A.; Sholkovitz, E. R. Trace element cycling in a subterranean estuary: Part 2. Geochemistry of the porewater. Geochim. Cosmochim. Acta 2006, 70, 811-826.

(6) Roy, M.; Martin, J. B.; Cherrier, J.; Cable, J. E.; Smith, C. G. Influence of sea level rise on iron diagenesis in an east Florida subterranean estuary. Geochim. Cosmochim. Acta 2010, 74, 5560-5573.

(7) Roy, M.; Martin, J. B.; Smith, C. G.; Cable, J. E. Reactivetransport modeling of iron diagenesis and associated organic carbon remineralization in a Florida (USA) subterranean estuary. Earth Planet. Sci. Lett. 2011, 304 (1-2), 191-201.

(8) Roy, M.; Martin, J. B.; Cable, J. E.; Smith, C. G. Variations of iron flux and organic carbon remineralization in a subterranean estuary caused by inter-annual variations in recharge. Geochim. Cosmochim. Acta 2013, 103, 301-315.

(9) Snyder, M.; Taillefert, M.; Ruppel, C. Redox zonation at the saline-influenced boundaries of a permeable surficial aquifer: Effects of physical forcing on the biogeochemical cycling of iron and manganese. J. Hydrol. 2004, 296, 164-178.

(10) McLachlan, A.; Brown, A. C. The ecology of sandy shores; Academic Press: Burlington, MA, 2006.

(11) Zhang, J.; Mandal, A. K. Linkages between submarine groundwater systems and the environment. Curr. Opin. Env. Sust. 2012, 4 (2), 219-226.

(12) Burnett, W. C.; Bokuniewicz, H.; Huettel, M.; Moore, W. S.; Taniguchi, M. Groundwater and pore water inputs to the coastal zone. Biogeochemistry 2003, 66, 3-33.

(13) Windom, H. L.; Moore, W. S.; Niencheski, L. F. H.; Jahnke, R. A. Submarine groundwater discharge: A large, previously unrecognized source of dissolved organic iron to the South Atlantic Ocean. Mar. Chem. 2006, 102 (3-4), 252-266.

(14) Rouxel, O.; Sholkovitz, E.; Charette, M. A.; Edwards, K. J. Iron isotope fractionation in subterranean estuaries. Geochim. Cosmochim. Acta 2008, 72 (14), 3413-3430.

(15) Kim, T. H.; Waska, H.; Kwon, E.; Suryaputra, I. G. N.; Kim, G. Production, degradation, and flux of dissolved organic matter in the subterranean estuary of a large tidal flat. Mar. Chem. 2012, 142-144, $1-10$.

(16) Chambers, R. M.; Odum, W. E. Porewater oxidation, dissolved phosphate and the iron curtain. Iron-phosphorus relations in tidal freshwater marshes. Biogeochemistry 1990, 10 (1), 37-52.

(17) Riedel, T.; Biester, H.; Dittmar, T. Molecular fractionation of dissolved organic matter with metal salts. Environ. Sci. Technol. 2012, 46 (8), 4419-26.

(18) Gomez-Saez, G. V.; Riedel, T.; Niggemann, J.; Pichler, T.; Dittmar, T.; Bühring, S. I. Interaction between iron and dissolved organic matter in a marine shallow hydrothermal system off Dominica Island (Lesser Antilles). Mar. Chem. 2015, 177, 677-686.

(19) Lv, J.; Zhang, S.; Wang, S.; Luo, L.; Cao, D.; Christie, P. Molecular-Scale Investigation with ESI-FT-ICR-MS on Fractionation of Dissolved Organic Matter Induced by Adsorption on Iron Oxyhydroxides. Environ. Sci. Technol. 2016, 50, 2328-2336.

(20) Seidel, M.; Beck, M.; Riedel, T.; Waska, H.; Suryaputra, I G. N. A; Schnetger, B.; Niggemann, J.; Simon, M.; Dittmar, T. Biogeochemistry of dissolved organic matter in an anoxic creek bank. Geochim. Cosmochim. Acta 2014, 140, 418-434.
(21) Seidel, M.; Beck, M.; Greskowiak, J.; Riedel, T.; Waska, H.; Suryaputra, I G. N. A.; Schnetger, B.; Niggemann, J.; Simon, M.; Dittmar, T. Benthic-pelagic coupling of nutrients and dissolved organic matter composition in an intertidal sandy beach. Mar. Chem. 2015, $176,150-163$.

(22) Reckhardt, A.; Beck, M.; Seidel, M.; Riedel, T.; Wehrmann, A.; Bartholomä, A.; Schnetger, B.; Dittmar, T.; Brumsack, H.-J. Carbon, nutrient and trace metal cycling in sandy sediments: A comparison of high-energy beaches and backbarrier tidal flats. Estuarine, Coastal Shelf Sci. 2015, 159, 1-14.

(23) Nierop, K. G. J.; Jansen, B.; Verstraten, J. M. Dissolved organic matter, aluminium, and iron interactions: precipitation induced by metal/carbon ratio, $\mathrm{pH}$ and competition. Sci. Total Environ. 2002, 300, 201-211.

(24) Koch, B. P.; Witt, M.; Engbrodt, R.; Dittmar, T.; Kattner, G. Molecular formulae of marine and terrigenous dissolved organic matter detected by electrospray ionization Fourier transform ion cyclotron resonance mass spectrometry. Geochim. Cosmochim. Acta 2005, 69 (13), 3299-3308.

(25) Sosa, O. A.; Gifford, S. M.; Repeta, D. J.; DeLong, E. F. High molecular weight dissolved organic matter enrichment selects for methylotrophs in dilution to extinction cultures. ISME J. 2015, 9, 2725-2739.

(26) Osterholz, H.; Niggemann, J.; Giebel, H.-A.; Simon, M.; Dittmar, T. Inefficient microbial production of refractory dissolved organic matter in the ocean. Nat. Commun. 2015, 6, 7422.

(27) Stubbins, A.; Spencer, R. G. M.; Chen, H.; Hatcher, P. G.; Mopper, K.; Hernes, P. J.; Mwamba, V. L.; Mangangu, A. M.; Wabakanghanzi, J. N.; Six, J. Illuminated darkness: Molecular signatures of Congo River dissolved organic matter and its photochemical alteration as revealed by ultrahigh precision mass spectrometry. Limnol. Oceanogr. 2010, 55 (4), 1467-1477.

(28) Zark, M.; Riebesell, U.; Dittmar, T. Effects of ocean acidification on marine dissolved organic matter are not detectable over the succession of phytoplankton blooms. Sci. Adv. 2015, 1 (9), e1500531.

(29) Dittmar, T.; Koch, B.; Hertkorn, N.; Kattner, G. A simple and efficient method for the solid-phase extraction of dissolved organic matter (SPE-DOM) from seawater. Limnol. Oceanogr.: Methods 2008, 6, 230-235.

(30) Röper, T.; Kröger, K. F.; Meyer, H.; Sültenfuss, J.; Greskowiak, J.; Massmann, G. Groundwater ages, recharge conditions, and hydrochemical evolution of a barrier island freshwater lens (Spiekeroog, Northern Germany). J. Hydrol. 2012, 454-455, 173186.

(31) Al-Raei, A. M.; Bosselmann, K.; Böttcher, M. E.; Hespenheide, B.; Tauber, F. Seasonal dynamics of microbial sulfate reduction in temperate intertidal surface sediments: controls by temperature and organic matter. Ocean Dynam. 2009, 59 (2), 351-370.

(32) Beck, M.; Brumsack, H.-J. Biogeochemical cycles in sediment and water column of the Wadden Sea: The example Spiekeroog Island in a regional context. Ocean Coast. Manage. 2012, 68, 102-113.

(33) Beck, M.; Dellwig, O.; Fischer, S.; Schnetger, B.; Brumsack, H.-J. Trace metal geochemistry of organic carbon-rich watercourses draining the NW German coast. Estuarine, Coastal Shelf Sci. 2012, $104-105,66-79$.

(34) Beck, M.; Reckhardt, A.; Amelsberg, J.; Bartholomä, A.; Brumsack, H.-J.; Cypionka, H.; Dittmar, T.; Engelen, B.; Greskowiak, J.; Hillebrand, H.; Holtappels, M.; Neuholz, R.; Köster, J.; Kuypers, M. M. M.; Massmann, G.; Meier, D.; Niggemann, J.; Paffrath, R.; Pahnke, K.; Rovo, S.; Striebel, M.; Vandieken, V.; Wehrmann, A.; Zielinski, O. The drivers of biogeochemistry in beach ecosystems: A cross-shore transect from the dunes to the low water line. Submitted to Marine Chemistry, 2016.

(35) Viollier, E.; Inglett, P. W.; Hunter, K.; Roychoudhury, A. N.; Van Cappellen, P. The ferrozine method revisited: $\mathrm{Fe}(\mathrm{II}) / \mathrm{Fe}(\mathrm{III})$ determination in natural waters. Appl. Geochem. 2000, 15, 785-790.

(36) Stubbins, A.; Dittmar, T. Low volume quantification of dissolved organic carbon and dissolved nitrogen. Limnol. Oceanogr.: Methods 2012, 10, 347-352. 
(37) Schnetger, B.; Lehners, C. Determination of nitrate plus nitrite in small volume marine water samples using vanadium(III)chloride as a reduction agent. Mar. Chem. 2014, 160, 91-98.

(38) Grasshoff, K.; Kremling, K.; Ehrhardt, M. Methods of seawater analysis; Wiley-VCH: Weinheim, Germany, 1990.

(39) Hawkes, J. A.; Hansen, C. T.; Goldhammer, T.; Bach, W.; Dittmar, T. Molecular alteration of marine dissolved organic matter under experimental hydrothermal conditions. Geochim. Cosmochim. Acta 2016, 175, 68-85.

(40) Green, N. W.; Perdue, E. M.; Aiken, G. R.; Butler, K. D.; Chen, H.; Dittmar, T.; Niggemann, J.; Stubbins, A. An intercomparison of three methods for the large-scale isolation of oceanic dissolved organic matter. Mar. Chem. 2014, 161, 14-19.

(41) Stenson, A. C.; Marshall, A. G.; Cooper, W. T. Exact Masses and Chemical Formulas of Individual Suwannee River Fulvic Acids from Ultrahigh Resolution Electrospray Ionization Fourier Transform Ion Cyclotron Resonance Mass Spectra. Anal. Chem. 2003, 75 (6), 12751284.

(42) Koch, B. P.; Dittmar, T.; Witt, M.; Kattner, G. Fundamentals of molecular formula assignment to ultrahigh resolution mass data of natural organic matter. Anal. Chem. 2007, 79 (4), 1758-63.

(43) Koch, B. P.; Dittmar, T. From mass to structure: an aromaticity index for high-resolution mass data of natural organic matter. Rapid Commun. Mass Spectrom. 2006, 20 (5), 926-932.

(44) Koch, B. P.; Dittmar, T. Corrigendum: From mass to structure: an aromaticity index for high-resolution mass data of natural organic matter. Rapid Commun. Mass Spectrom. 2016, 30 (1), 250.

(45) Šantl Temkiv, T.; Finster, K.; Dittmar, T.; Hansen, B. M.; Thyrhaug, R.; Nielsen, N. W.; Karlson, U. G. Hailstones: a window into the microbial and chemical inventory of a storm cloud. PLoS One 2013, 8 (1), e53550.

(46) Seidel, M.; Yager, P. L.; Ward, N. D.; Carpenter, E. J.; Gomes, H. R.; Krusche, A. V.; Richey, J. E.; Dittmar, T.; Medeiros, P. M. Molecular-level changes of dissolved organic matter along the Amazon River-to-ocean continuum. Mar. Chem. 2015, 177, 218-231.

(47) Peter, S.; Isidorova, A.; Sobek, S. Enhanced carbon loss from anoxic lake sediment through diffusion of dissolved organic carbon. J. Geophys. Res.: Biogeosci. 2016, 121 (7), 1959-1977.

(48) Michael, H. A.; Mulligan, A. E.; Harvey, C. F. Seasonal oscillations in water exchange between aquifers and the coastal ocean. Nature 2005, 436, 1145-1148.

(49) Lalonde, K.; Mucci, A.; Ouellet, A.; Gélinas, Y. Preservation of organic matter in sediments promoted by iron. Nature 2012, 483, 198-200.

(50) Eglinton, T. I. Geochemistry: A rusty carbon sink. Nature 2012, 483, 165-166. 